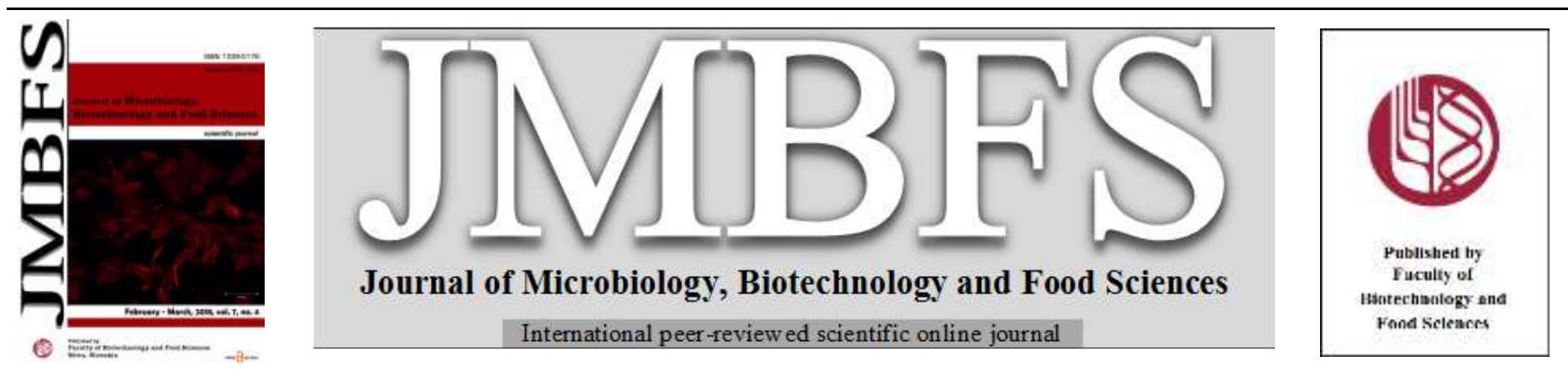

\title{
INHIBITION OF ADHESION OF UROPATHOGENIC ESCHERICHIA COLI TO CANINE AND FELINE UROEPITHELIAL CELLS BY AN EXTRACT FROM CRANBERRY
}

\author{
Gilles Mayot, Camille Secher, and Patrick Di Martino* \\ Address(es): Laboratoire ERRMECe-EA1391, Université de Cergy-Pontoise, rue Descartes site de Neuville-sur-Oise, 95031 Cergy-Pontoise cedex, France.
}

*Corresponding author: Patrick.di-martino@u-cergy.fr

doi: 10.15414/jmbfs.2018.7.4.404-406

\section{ARTICLE INFO}

Received 15. 3. 2017

Revised 19. 12. 2017

Accepted 10.1.2018

Published 1. 2. 2018

Short communication

$\operatorname{oren}(\mathrm{O}$ access

\begin{abstract}
Uropathogenic Escherichia coli (UPEC) is the main infectious agent of urinary tract infections (UTI) in humans, dogs and cats. Dietary consumption of cranberries is thought to be associated with prevention of UTI in humans based on decreased adhesion of UPEC to uroepithelial cells. The present study evaluated the impact of cranberry extract addition on the attachment of UPEC to canine MadinDarby Canine Kidney and Crandell-Rees Feline Kidney uroepithelial cells. When the extract was present during bacterial growth or only during adhesion tests, a dose-dependent decrease of UPEC adhesion to all cell types was observed. Bacterial growth was weakly decreased only in the presence of the highest concentration of cranberry extract showing that the anti-adherence effect did not require a bacterial growth inhibitory effect. In conclusion, the addition of cranberry extract has preventive effects on the in vitro bacterial attachment to canine and feline uroepithelial cells in a dose dependent way.
\end{abstract}

Keywords: urinary tract infection, dog, cat, Escherichia coli, Cranberry

\section{INTRODUCTION}

Bacterial urinary tract infections (UTI) are common in dogs but less common in cats (Litster et al., 2011; Thompson et al., 2011). The prevalence of UTIs is increased in small animals that have their urinary tract defence mechanisms altered by the effects of other diseases and/or by the treatment (Norris $\boldsymbol{e t}$ al., 2000; Mayer-Roenne et al., 2007). Like for humans, Escherichia coli is a major etiologic agent of UTIs for many animals such as dogs and cats (Köhler and Dobrindt, 2011). E. coli is part of the commensal intestinal microflora of healthy populations and normally colonize the gut just after birth. Once E. coli gets access to the urogenital tract from faecal contamination, it can ascend the urinary tract, colonize the bladder and induce cystitis, or colonize the kidney and induce pyelonephritis. Ascending uropathogenic E. coli (UPEC) strains usually have a particular repertoire of virulence genes including genes encoding for adherence factors such as fim (type 1 pili), pap (pilus associated with pyelonephritis), sfa (S fimbriae), and genes encoding for exotoxins such as $h l y$ ( $\alpha$-hemolysin), and cnfl (cytotoxic necrotizing factor 1). Some E. coli isolates from humans, dogs, and cats have close similarity in the genomic backbone and virulence genotype being sometimes qualified as uropathogenic clones (Johnson et al., 2000; Féria et al., 2001; Johnson et al., 2008a; Johnson et al., 2008b).

Like for humans, UTIs of pets are usually treated with antibiotics during the acute phase of infection, and, antibiotics can be used for long-term prophylaxis for individuals with recurrent infections. Frequent or long-term antibiotic use is known to induce antibiotic resistance and can result in vaginal and intestinal dysbiosis. This is an illustration of the need to develop complementary medicine also in veterinary medicine (Raditic, 2015). Dietary consumption of cranberries has long been associated with the maintenance of urinary tract health in humans (Hisano et al., 2012). There is scientific evidence showing that human dietary consumption of cranberry can provide a degree of protection against adhesion to urinary epithelial cells by different UPEC strains (Sobota, 1984; Di Martino et al., 2006). Even if there is a debate about the real benefits of cranberry consumption to prevent urinary tract infections (Jepson et al., 2012), there are experimental data showing that a cranberry preparation can completely prevent recurrent UTIs in women (Bailey et al., 2007; Efros $\boldsymbol{e t}$ al., 2010). Like in humans, cranberry components could be used to prevent urinary tract infections in dogs and cats. There is a need for studies evaluating the use of cranberry to prevent urinary tract infections in dogs and cats based on the inhibition of bacterial adhesion to canine and feline uroepithelial cells.

\section{MATERIAL AND METHODS}

To determine whether cranberry can inhibit the $E$. coli adherence to pets urinary epithelial cells in vitro, we tested the adherence to canine Madin-Darby Canine Kidney (MDCK) and feline Crandell-Rees Feline Kidney (CRFK) urinary epithelial cells of the E. coli G1473 strain harbouring the papC gene and expressing type 1 pili, previously isolated from human patients with symptomatic UTI (Di Martino et al., 2006) in the presence of different concentrations of a cranberry extract. Bacterial adherence to urinary epithelial cells was carried out as previously described (Di Martino et al., 2000). The human bladder epithelial T24 cell line (ATCC HTB-4) was used as a control. After growth at $37{ }^{\circ} \mathrm{C}$ for $24 \mathrm{~h}$ in the urinary epithelial cell lines growth media (Dulbecco's Modified Eagle Medium $+1 \mathrm{~g} / \mathrm{L}$ D-glucose or McCoy's 5a medium depending on the corresponding cell line) in static conditions, bacteria were harvested by centrifugation, suspended in the same basic cell culture medium (Eurobio, Les Ulis, France), and incubated with urinary epithelial cells at $37^{\circ} \mathrm{C}$ for $3 \mathrm{~h}$. After washes with PBS, the cells were fixed in ethanol, stained with $20 \%$ Giemsa (v/v), and examined microscopically under oil immersion. Cranberry extract was added to the medium at the desired concentration either during bacterial growth or during the adherence test. Thus, the presence of cranberry during bacterial growth and absence of cranberry during the adherence test corresponded to condition 1; the absence of cranberry during bacterial growth and presence of cranberry during the adherence test corresponded to condition 2 . The cranberry extract containing at least $25 \%$ proanthocyanidins was purchased from the Phenolics, LLC. (Omaha, NE, USA). The extract was dissolved in the urinary epithelial cell lines growth media to obtain a stock solution calibrated at a concentration of $5 \mathrm{mg} / \mathrm{ml}$. The stock solution was sterilized by filtration $(0.45$ $\mu \mathrm{m})$ before use. Serial twofold dilutions of the cranberry stock solution were done in the same urinary epithelial cell line growth medium before use, depending on the experiments. 


\section{RESULTS AND DISCUSSION}

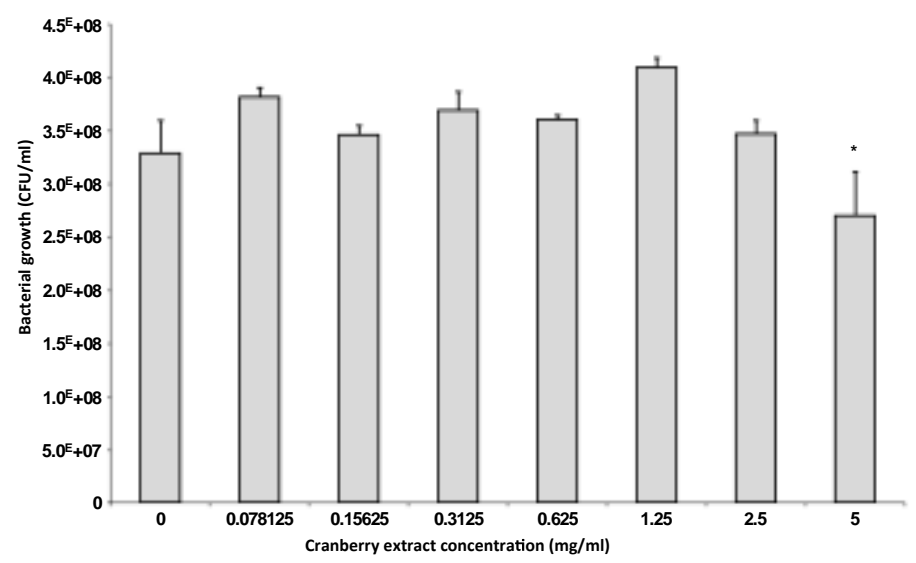

Figure 1 Effects of different concentrations of cranberry extract on the growth of Escherichia coli G1473 in McCoy's 5a medium. Means \pm standard errors to the means $(\mathrm{n}=3)$. The statistical significance of differences observed between cranberry extract concentrations was evaluated with the Dunn's multiple comparison test following the Kruskal-Wallis test. *, $P<0.05$.

As shown in Figure 1, bacterial growth at $24 \mathrm{~h}$ was weakly decreased in the presence of cranberry extract only for the higher concentration of $5 \mathrm{mg} / \mathrm{ml}(P<$ 0.05 ). A significant inhibition of $E$. coli growth has been previously demonstrated with increasing concentration of cranberry proanthocyanidin in vitro (Margetis et al., 2015).

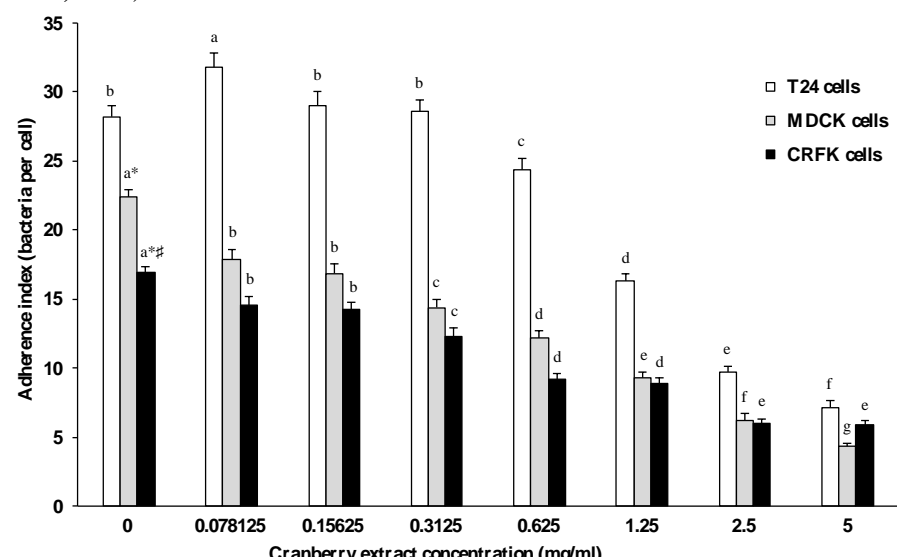

Figure 2 Effects of different concentrations of cranberry extract on bacterial adherence to human T24, canine MDCK, and feline CRFK urinary epithelial cells of Escherichia coli G1473: presence of cranberry during bacterial growth and absence of cranberry during the adherence test (condition 1). Means \pm standard errors to the means $(\mathrm{n}=3 \times 50)$. Adherence indices represent the average number of bacteria per cell determined by examining 50 cells under 3 independent experiments. The statistical significance of differences observed between cranberry extract concentrations was evaluated for each cell line with the Newman-Keuls test following the one-way ANOVA test. At $0 \mathrm{mg} / \mathrm{mL}$, the statistical significance of differences observed between the cell lines was analysed using the Student's t-test. *, Value differs significantly $(P<0.001)$ from the value obtained with T24 cells. \#, Value differs significantly $(P<0.001)$ from the value obtained with MDCK cells.

The adherence of the G1473 UPEC strain was first tested with the three epithelial cell lines without cranberry extract. In the absence of cranberry, the G1473 strain adhered to human T24, feline CRFK, and canine MDCK cells with adherence indices of $28.2 \pm 0.78,16.9 \pm 0.42$ and $22.40 \pm 0.54$ bacteria per cell, respectively (Figure 2). The adherence index of the G1473 strain was significantly different between the three cell lines, being highest with human T24 cells and the lowest with feline CRFK cells. UPEC adherence to feline CRFK has not been documented before and only one published study analysed UPEC interactions with MDCK cells (Chou et al., 2016). Chou et al. showed that the adherence indices of the three UPEC strains isolated from dogs with UTI were around 100 bacteria per MDCK cell. In the present study, the adherence indices of the three UPEC strains isolated from humans with UTI varied from about 12 to about 25 bacteria per cell, depending on the strain. It is not possible to compare the two studies since Chou et al. have used MDCK cells after methanol fixation while we used living cells. Furthermore, the protocol used by Chou et al. comprises two successive stages of adhesion and bacterial growth separated by washing whereas our study employed only an adhering step followed by washings, as in most published studies (Zafriri et al., 1989; Di Martino et al., 2006). Anyway, adhesion indices are high in both studies showing a strong adhesion of UPEC to MDCK cells in vitro. The results presented here showed that one UPEC strain isolated from a human patient with symptomatic UTI adhered efficiently not only to human T24 cells but also to feline and canine kidney epithelial cell lines CRFK and MDCK in vitro. Thus, these two animal cell lines may be useful models to study the interactions between bacterial pathogens and urinary epithelial cells in a canine or feline infection context. The demonstration that a human UPEC strain adheres efficiently to human, canine, and feline urinary epithelial cells is consistent with cross-species exchange of $E$. coli clones (Johnson et al., 2000; Johnson et al., 2008). Indeed, similar E. coli uropathogens may be capable of infecting dogs, cats and humans (Low et al., 1988; Johnson et al., 2008).

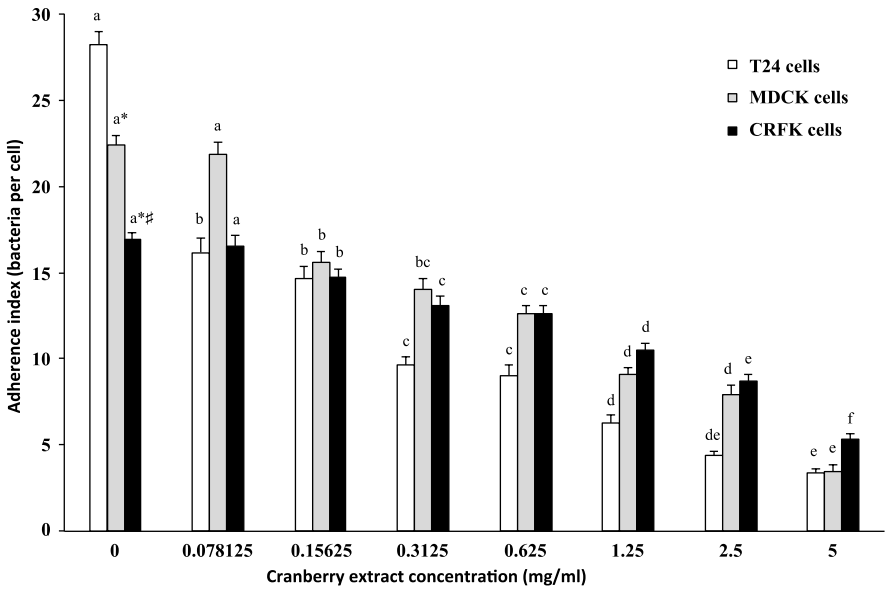

Figure 3 Effects of different concentrations of cranberry extract on bacteria adherence to human T24, canine MDCK, and feline CRFK urinary epithelial cells of Escherichia coli G1473: absence of cranberry during bacterial growth and presence of cranberry during the adherence test (condition 2). Means \pm standard errors to the means $(n=3 \times 50)$. Adherence indices represent the average number of bacteria per cell determined by examining 50 cells under 3 independent experiments. The statistical significance of differences observed between cranberry extract concentrations was evaluated for each cell line with the Newman-Keuls test following the one-way ANOVA test. At $0 \mathrm{mg} / \mathrm{mL}$, the statistical significance of differences observed between the cell lines was analysed using the Student's t-test. *, Value differs significantly $(P<0.001)$ from the value obtained with T24 cells. \#, Value differs significantly $(P<0.001)$ from the value obtained with MDCK cells.

The effect of cranberry extract on bacterial adherence to urinary epithelial cells was tested in two different conditions: presence of cranberry during bacterial growth and absence of cranberry during the adherence test (condition 1); absence of cranberry during bacterial growth and presence of cranberry during the adherence test (condition 2). Serial twofold dilutions of the cranberry extract stock solution were first tested with the G1473 strain (Figure 2 and Figure 3). For condition 1, G1473 adherence to the three cell lines was decreased after bacterial growth in the presence of cranberry extract from 5 to $0.625 \mathrm{mg} / \mathrm{ml}$ for adherence to T24, CRFK and MDCK cells (Figure 2). Adhesion inhibition to MDCK and CRFK cells was observed from a concentration of $0.078125 \mathrm{mg} / \mathrm{ml}$ of cranberry extract (Figure 2). For the highest cranberry extract concentration of $5 \mathrm{mg} / \mathrm{ml}$, G1473 adherence was reduced by $78.5 \%, 62.9 \%$ and $77.7 \%$ for T24, CRFK and MDCK cells, respectively. For the three epithelial cell lines tested, increasing the concentration of cranberry extract led to a more pronounced decrease in bacterial adhesion indicating a dose-dependent inhibitory effect. For condition 2, G1473 adherence to the three cell lines was decreased in the presence of cranberry extract for a large range of concentrations: from 5 to $0.15625 \mathrm{mg} / \mathrm{ml}$ for adherence to T24, CRFK and MDCK cells (Figure 3). Adhesion inhibition to T24 cells was observed from a concentration of $0.078125 \mathrm{mg} / \mathrm{ml}$ of cranberry extract (Figure 3). For the highest cranberry extract concentration of $5 \mathrm{mg} / \mathrm{ml}$, bacterial adherence was reduced by $85.4 \%, 70.5 \%$ and $86.3 \%$ for T24, CRFK and MDCK cells, respectively. Again, a dose-dependent inhibitory effect of cranberry extract on the adherence of $E$. coli was observed (Figure 3 ). Our results clearly showed that the presence of a cranberry extract, either during bacterial growth or during the adherence test, is associated with a dose dependent decrease in $E$. col adherence to human, canine and feline urinary epithelial cells in vitro. Thus, the mechanism of action of cranberry constituents to decrease $E$. coli adherence to urinary epithelial cells is not dependent upon the host species cell line used. Studies on the health effects of cranberry or cranberry extracts through dietary supplementation are very limited in animals. Cranberry supplementation in drinking water has been shown to have a potential preventive effect on the development of bacterial prostatitis in a rat infection model (Kim et al., 2011) Pretreatment with cranberry significantly decreased the degree of inflammation of the prostate but, did not decrease significantly the infection rate and bacterial growth in the urinary tract, although there was a trend towards improvement of 
these factors. Dietary supplementation of cranberry pomace has been shown to partially ameliorate metabolic factors associated with high fructose feeding in growing Sprague- Dawley rats (Khanal et $\boldsymbol{a l}$., 2010). Cranberry extracts have been evaluated as alternatives to traditional antibiotics in broiler chicken production (Leusink $\boldsymbol{e t}$ al., 2010). The growth performance of broiler chickens was not statistically improved when they were fed diets containing cranberry extracts, but the use of a cranberry extract was associated with a decrease of early mortality due to yolk sac infection, omphalitis, crossbeak, starve-out, and dehydration (Leusink et al., 2010). In a recent study, powdered cranberry extract dietary supplementation was evaluated for prevention of UTI in dogs with a history of recurrent UTIs and for prevention of UPEC adherence to MDCK cells in vitro (Chou et al., 2016). None of the 6 dogs fed with cranberry extract developed UTIs during the 6 months period of the assay, and no adverse effect was observed. Urine samples collected after administration of the cranberry extract were shown to decrease UPEC adherence to MDCK cells in vitro but did not induce bacteriostasis in a plate-diffusion assay in vitro.

In conclusion, the results presented here provide evidence that cranberry extract supplementation has an inhibitory effect on UPEC adherence to canine and feline urinary epithelial cells in vitro. As previously published in humans and dogs (Di Martino et al., 2006; Chou et al., 2016), ex vivo studies are needed to demonstrate the presence of an inhibitory activity on $E$. coli adherence to cats uroepithelial cells in the urine of healthy subjects after dietary consumption of cranberry.

Acknowledgements: This work was supported in part by a grant from Nestle Purina Research (Nestec Ltd., Vevey, Switzerland). The authors wish to thank Dr. Hui Xu for helpful discussion.

\section{REFERENCES}

Bailey, D.T., Dalton, C., Joseph Daugherty, F., \& Tempesta, M.S. (2007). Can a concentrated cranberry extract prevent recurrent urinary tract infections in women? A pilot study. Phytomedicine, 14, 237-241. https://doi.org/10.1016/j.phymed.2007.01.004

Chou, H.I., Chen, K.S., Wang, H.C., \& Lee, W.M. (2016). Effects of cranberry extract on prevention of urinary tract infection in dogs and on adhesion of Escherichia coli to Madin-Darby canine kidney cells. Am J Vet Res, 77, 421-427. https://doi.org/10.2460/ajvr.77.4.421

Di Martino, P., Rebière-Huët, J., and Hulen, C. (2000). Effects of antibiotics on adherence of Pseudomonas aeruginosa and Pseudomonas fluorescens to A549 pneumocyte cells. Chemotherapy, 46, 129-134. http://www.karger.com/doi/10.1159/000007267

Di Martino, P., Agniel, R., David, K., Templer, C., Gaillard, J.L., Denys, P., \& Botto, H. (2006). Reduction of Escherichia coli adherence to uroepithelial bladder cells after consumption of cranberry juice: a double-blind randomized placebo-controlled cross-over trial. World $J$ Urol, 24, 21-27. https://doi.org/10.1007/s00345-005-0045-z

Efros, M., Bromberg, W., Cossu, L., Nakeleski, E., \& Katz, A.E. (2010). Nove concentrated cranberry liquid blend, UTI-STAT with Proantinox, might help prevent recurrent urinary tract infections in women. Urology, 76, 841-845 https://doi.org/10.1016/j.urology.2010.01.068

Féria, C., Machado, J., Correia, J.D., Gonçalves, J., \& Gaastra, W. (2001)

Virulence genes and $\mathrm{P}$ fimbriae PapA subunit diversity in canine and feline uropathogenic Escherichia coli. Vet Microbiol, 82, 81-89. http://dx.doi.org/10.1016/S0378-1135(01)00375-3

Hisano, M., Bruschini, H., Nicodemo, A.C., \& Srougi, M. (2012). Cranberries and lower urinary tract infection prevention. Clinics (Sao Paulo). 67(6), 661-668. http://dx.doi.org/10.6061/clinics/2012(06)18

Jepson, R.G., Williams, G., \& Craig, J.C. (2012). Cranberries for preventing urinary tract infections. Cochrane Database Syst Rev, 10:CD001321. https://doi.org/10.1590/1516-3180.20131315T1

Johnson, J.R., O'Bryan, T.T., Low, D.A., Ling, G., Delavari, P., Fasching, C., Russo, T.A., Carlino, U., \& Stell, A.L. (2000). Evidence of commonality between canine and human extraintestinal pathogenic Escherichia coli strains that express papG allele III. Infect Immun, 68, 3327-3336. https://doi.org/10.1128/IAI.68.6.3327-3336.2000

Johnson, J.R., Owens, K., Gajewski, A., \& Clabots, C. (2008a). Escherichia coli colonization patterns among human household members and pets, with attention to acute urinary tract infection. J Infect Dis, 197, 218-224. https://doi.org/10.1086/524844

Johnson, J.R., Johnston, B., Clabots, C.R., Kuskowski, M.A., Roberts, E., \& DebRoy, C. (2008b). Virulence genotypes and phylogenetic background of Escherichia coli serogroup O6 isolates from humans, dogs, and cats. J Clin Microbiol, 46, 417-422. https://doi.org/10.1128/JCM.00674-07

Khanal, R.C., Howard, L.R., Wilkes, S.E., Rogers, T.J., \& Prior, R.L. (2010) Cranberry pomace partially ameliorates metabolic factors associated with high fructose feeding in growing Sprague-Dawley rats. J Funct Foods, 2, 284-291. http://dx.doi.org/10.1016/j.jff.2010.11.003

Kim, S.H., Ha, U.S., Lee, H.R., Sohn, D.W., Lee, S.J., Kim, H.W., Han, C.H., Lee, C.B., \& Cho, Y.H. (2011). Do Escherichia coli extract and cranberry exert preventive effects on chronic bacterial prostatitis? Pilot study using an animal model. J Infect Chemother, 17, 322-326. https://doi.org/10.1007/s10156-010 0170-5

Köhler, C.D., \& Dobrindt, U. (2011). What defines extraintestinal pathogenic Escherichia coli? Int J Med Microbiol, 301, 642-647. https://doi.org/10.1016/j.ijmm.2011.09.006

Leusink, G., Rempel, H., Skura, B., Berkyto, M., White, W., Yang, Y., Rhee, J.Y., Xuan, S.Y., Chiu, S., Silversides, F., Fitzpatrick, S., \& Diarra, M.S. (2010) Growth performance, meat quality, and gut microflora of broiler chickens fed with cranberry extract. Poult Sci, 89, 1514-1523. https://doi.org/10.3382/ps.2009 $\underline{00364}$

Litster, A., Thompson, M., Moss, S., \& Trott, D. (2011). Feline bacterial urinary tract infections: An update on an evolving clinical problem. Vet J, 187, 18-22. https://doi.org/10.1016/j.tvj1.2009.12.006

Low, D.A., Braaten, B.A., Ling, G.V., Johnson, D.L., \& Ruby, A.L. (1988) Isolation and comparison of Escherichia coli strains from canine and human patients with urinary tract infections. Infect Immun, 56, 2601-2609. https://www.ncbi.nlm.nih.gov/pmc/articles/PMC259618/

Margetis, D., Roux, D., Gaudry, S., Messika, J., Bouvet, O., Branger, C. Ponnuswamy, P., Oufella, H.A., Dreyfuss, D., Denamur, E., Ricard, J.D. (2015). Effects of Proanthocyanidins on Adhesion, Growth, and Virulence of Highly Virulent Extraintestinal Pathogenic Escherichia coli Argue for Its Use to Treat Oropharyngeal Colonization and Prevent Ventilator-Associated Pneumonia. Crit Care Med, 43(6), e170-178. https://doi.org/10.1097/CCM.0000000000000972

Mayer-Roenne, B., Goldstein, R.E., \& Erb, H.N. (2007). Urinary tract infections in cats with hyperthyroidism, diabetes mellitus and chronic kidney disease. $J$ Feline Med Surg, 9, 124-132. https://doi.org/10.1016/i.jfms.2006.09.004

Norris, C.R., Williams, B.J., Ling, G.V., Franti, C.E., Johnson, D.L., \& Ruby, A.L. (2000). Recurrent and persistent urinary tract infections in dogs: 383 cases (1969-1995). J Am Anim Hosp Assoc, 36, 484-492. https://doi.org/10.5326/15473317-36-6-484

Raditic, D.M. (2015). Complementary and integrative therapies for lower urinary tract diseases. Vet Clin North Am Small Anim Pract, 45, 857-878. https://doi.org/10.1016/j.cvsm.2015.02.009

Sobota, A.E. (1984). Inhibition of bacterial adherence by cranberry juice: potential use for the treatment of urinary tract infection. $J$ Urol, 131, 1013-1016 https://www.ncbi.nlm.nih.gov/pubmed/6368872

Thompson, M.F., Litster, A.L., Platell, J.L., \& Trott, D.J. (2011). Canine bacterial urinary tract infections: new developments in old pathogens. Vet J, 190 22-27. http://dx.doi.org/10.1016/j.tvjl.2010.11.013

Zafriri, D., Ofek, I., Adar, R., Pocino, M., \& Sharon, N. (1989). Inhibitory activity of cranberry juice on adherence of type 1 and type $\mathrm{P}$ fimbriated Escherichia coli to eucaryotic cells. Antimicrob Agents Chemother, 33, 92-98. https://www.ncbi.nlm.nih.gov/pmc/articles/PMC171427/ 